\title{
Percepções de extensionistas rurais sobre educação alimentar e nutricional
}

\author{
Perceptions of rural extension workers on food and nutritional education \\ Les perceptions des conseillers techniques sur education alimentaire et \\ nutritionnelle
}

\author{
Percepciones sobre la educación alimentaria y nutricional en extensionistas \\ rurales
}

\author{
Nádia Rosana Fernandes Oliveira ${ }^{1}$ \\ Patricia Constante Jaime ${ }^{2}$
}

Recebido em 16/01/2017; revisado e aprovado em 17/04/2017; aceito em 26/04/2017

DOI: http://dx.doi.org/10.20435/inter.v18i3.1470

\begin{abstract}
Resumo: Trata-se de estudo com abordagem qualitativa, cujo objetivo foi analisar a percepção de extensionistas rurais sobre a educação alimentar e nutricional (EAN) em sua prática de trabalho. A compreensão e a estrutura de significações da EAN foram visualizadas sob três eixos: reconhecimento e não reconhecimento da EAN; a EAN como um dos temas da dimensão "social"; a EAN como sinônimo de Segurança Alimentar e Nutricional Palavras-chave: educação alimentar e nutricional; extensão rural; segurança alimentar e nutricional.

Abstract: This is a qualitative study whose objective was to analyze the perception of rural extension workers on food and nutrition education in their work practice. The understanding and the structure of meanings of the Food and Nutrition Education were considered under three areas: recognition and non-recognition of Food and Nutrition; Food and Nutrition Education as one of the themes of the "social" dimension; Food
\end{abstract} and Nutrition Education as a synonym for Food and Nutrition Security.

Key words: food and nutrition education; rural development; food and nutrition security.

Résumé: Ce travail a cherché à comprendre et analyser la perception Conseil Technique, Social et Environnemental aux "assentamentos rurais" dans le Rio Grande do Sul sur l'éducation alimentaire et nutritionnelle (EAN) dans leur pratique de travail. La compréhension et la structure du sens de EAN ont été consultés dans trois domaines: la reconnaissance et la non-reconnaissance de EAN; EAN comme l'un des thèmes de la dimension «sociale»; EAN comme synonyme de sécurité alimentaire et nutritionnelle.

Mots-clés: éducation alimentaire et nutritionnelle; developpement rural; securite alimentaire et nutritionnelle.

Resumen: Con el objetivo de analizar la percepción de extensionistas rurales acerca de la educación alimentaria y nutricional en sus prácticas de trabajo fue realizado un estudio de abordaje cualitativo. La comprensión y estructura del significado de la Educación Alimentaria y Nutricional fueron visualizados sobre tres ejes: reconocimiento y no reconocimiento de la Educación Alimentar y Nutricional; Educación Alimentar y Nutricional como uno de los temas de la dimensión "social"; Educación Alimentar y Nutricional como sinónimo de seguridad Alimentaria y Nutricional.

Palabras clave: educación alimentar y nutricional; desenvolvimiento rural; seguridad alimentaria y nutricional.

\section{INTRODUÇÃO}

A extensão rural no Rio Grande do Sul (RS) segue o cenário institucional nacional, orientado pela Política Nacional de Assistência Técnica e Extensão Rural (PNATER) (BRASIL, 2010), na qual o Estado cumpre o papel de coordenar e financiar a oferta de serviços de extensão rural, participando do controle, e não de sua execução. A Política foi construída para atender exclusivamente o público categorizado como agricultores familiares a partir do desenvolvimento do campo baseado na sustentabilidade e nos preceitos da agroecologia. Tem como pressuposto

\footnotetext{
${ }^{1}$ Universidade Federal do Pampa (Unipampa), Itaqui, Rio Grande do Sul, Brasil.

${ }^{2}$ Universidade de São Paulo (USP), São Paulo, Brasil.
} 
uma orientação técnica baseada nas metodologias participativas com a intenção de promover o desenvolvimento endógeno dos agricultores.

Nos marcos da PNATER, foi criado o Programa de Assessoria Técnica Social e Ambiental para os Assentamentos da Reforma Agrária (ATES) em 2004. No caso do estado do RS, a ATES garante a cobertura da totalidade das famílias assentadas. Estruturalmente, o Programa se organiza por gestão pública pelo Instituto Nacional de Colonização e Reforma Agrária (INCRA) e controle social pelos Conselhos da ATES, agentes públicos de assessoria ao Programa pelos Assessores Técnicos Pedagógicos (ATPs), agentes públicos executores pelas prestadoras de serviços de ATES. No estado, o Programa de ATES é composto por 20 equipes técnicas, com 147 extensionistas, 10.958 famílias, 302 assentamentos, em 83 municípios (INCRA, 2008; 2013).

Firmando-se em Paulo Freire (1983), compreende-se a ação extensionista com pressupostos educativo-comunicativos. Estando nesse contexto, os serviços de ATES baseiam-se no contato entre pessoas, na busca para educação de modo que, ao realizar a extensão rural, trata dos diversos elementos do cotidiano dos agricultores.

Reconhecendo a educação alimentar e nutricional como campo interdisciplinar (BOOG, 1999; 2013), estando os serviços de extensão rural ocupados com os modos de geração de conhecimento e de protagonismo dos agricultores no sistema alimentar, o objetivo deste artigo foi analisar a percepção de extensionistas rurais sobre a educação alimentar e nutricional em sua prática de trabalho.

\section{PERCURSO METODOLÓGICO}

Trata-se de estudo com abordagem qualitativa, envolvendo a produção de dados a partir de entrevistas individuais, as quais visaram apreender os sentidos das práticas reconstruídas pelos sujeitos de estudo. Desse modo, trabalharam-se as dimensões de percepções, significados e sentidos sobre a educação alimentar e nutricional no trabalho da ATES para a Reforma Agrária no estado do RS.

A seleção dos indivíduos seguiu metodologia proposta por Ritchie et al. (2003) para amostragem propositiva, buscando captar pessoas de todos os segmentos que se relacionam com o trabalho da ATES no RS, sendo sujeitos do estudo aqueles que estavam vinculados às instituições na ocasião da produção de dados.

Foram realizadas 18 entrevistas, entre novembro de 2015 e abril de 2016, com um gestor público da coordenação estadual do Programa de ATES (INCRA), seis Assessores Técnicos Pedagógicos (Universidade Federal de Santa Maria/INCRA), coordenadores e técnicos extensionistas rurais das prestadoras de serviços de ATES (quatro entrevistados do Centro de Tecnologias Alternativas e Populares/CETAP; dois entrevistados da Cooperativa de Prestação de Serviços Técnicos/COPTEC; cinco entrevistados da Empresa de Assistência Técnica e Extensão Rural/EMATER). Desses entrevistados, foram inclusos profissionais com formação em agronomia, pedagogia, nutrição, serviço social, técnico agrícola, tecnólogo em agroecossistemas e em desenvolvimento. Os entrevistados tinham entre dois e oito anos de atividade enquanto extensionistas rurais na ATES.

Foi realizado pré-teste do roteiro de entrevista em local e com sujeitos de estudo distintos daqueles da pesquisa. As questões estruturaram-se a partir de eixos sobre as características e demandas do trabalho e acerca da percepção sobre a educação alimentar e nutricional no cotidiano do trabalho da ATES.

INTERAÇÕES, Campo Grande, MS, v. 18, n. 3, p. 41-54, jul./set. 2017. 
O processo de entrevistas foi contínuo até que a investigadora atinjisse a saturação de dados, utilizada como elemento de medida para o entendimento da pesquisadora sobre os temas estudados e não somente de repetições nas falas dos sujeitos entrevistados. Para dar apoio à técnica de saturação de dados, as entrevistas foram transcritas tão logo haviam sido realizadas (RITCHIE; LEWIS; ELAM, 2003).

A análise dos dados foi realizada a partir de quatro etapas: 1) audição das narrativas gravadas e leitura do diário de campo; 2) análise a partir da transcrição e leitura vertical do material produzido; 3 ) impregnação de temas, cultura, universo simbólico e representações sociais atribuídas às experiências introjetadas de cada sujeito entrevistado; 4) e a análise horizontal da totalidade das entrevistas a fim de analisar os temas previstos e os temas emergidos das narrativas.

$\mathrm{Na}$ análise, buscou-se identificar as narrativas descritivas e as narrativas interpretativas; relato de fatos e exposição de valores. Conforme aponta Canesqui (2007), a diferença entre a análise narrativa e as outras formas de produção de dados qualitativos está exatamente na centralidade na maneira como as pessoas narram suas histórias, que são tomadas como um todo e interpretadas dentro do contexto no qual foram geradas.

O procedimento de tratamento dos dados foi fundamentado no método de interpretação de sentidos, baseados em princípios hermenêutico-dialéticos. Segundo Gomes (2013), esse método busca interpretar os contextos, as razões e as lógicas de falas, ações e inter-relações entre grupos e instituições. O princípio hermenêutico propõe uma análise compreensiva, mais do que explicativa dos fenômenos a partir da história concreta dos sujeitos.

O estudo foi aprovado pelo Comitê de Ética em Pesquisa FSP/USP sob número CAAE 50953815.9.0000.5421.

\section{RESULTADOS E DISCUSSÃO}

As entrevistas proporcionaram analisar dados semelhantes e, ao mesmo tempo, muito heterogêneos. Os significados e os sentidos atribuídos à educação alimentar e nutricional nos serviços de ATES foram categorizados a partir das narrativas descritivas e das narrativas interpretativas.

Nas primeiras, os informantes constataram ações de seu fazer cotidiano, desenvolveram pensamentos e discursos que já estavam elaborados a priori. Na segunda categoria, os sujeitos entrevistados reelaboraram os temas questionados, interpretaram sua própria realidade com vistas a responder ao que foi proposto. Nesse sentido, algumas narrativas falam por si, expressando fortemente algum tema que foi possível de ser refletido anteriormente ou algo que é muito rotineiro. Geralmente, as narrativas interpretativas foram expressas a partir de uma reelaboração de práticas sutis, que podem não ter sido refletidas antes do momento da entrevista ou que fazem parte de algum tema que precisa ser analisado/reelaborado pelo entrevistado, para que, então, seja dito ao entrevistador.

Assim, os resultados apresentados são decorrentes de compreensão, significados e sentidos do que e de como é a educação alimentar e nutricional para os atores sociais envolvidos na Assessoria Técnica Social e Ambiental para os Assentamentos da Reforma Agrária no Rio Grande do Sul. 


\section{EDUCAÇÃO ALIMENTAR E NUTRICIONAL NA ATES}

A compreensão e a estrutura de significações da EAN foram visualizadas sob três eixos, sendo as categorias emergentes: reconhecimento e não reconhecimento da EAN na ATES; a EAN como um dos temas da dimensão 'social' da ATES; a EAN como sinônimo de Segurança Alimentar e Nutricional (SAN).

\section{RECONHECIMENTO E NÃO RECONHECIMENTO}

O reconhecimento e os significados da presença de educação alimentar e nutricional na ATES foram enunciados em todas as narrativas dos técnicos extensionistas das prestadoras de serviços de ATES. Narrativas de gestores e assessores técnicos pedagógicos também reconheceram a educação alimentar e nutricional, entretanto, deste último grupo, três entrevistados não reconheceram, em suas narrativas, a presença de práticas, planos ou propostas de ação relacionadas à EAN na ATES.

O reconhecimento da educação alimentar e nutricional foi relacionado diretamente com abordagens de extensão rural que privilegiavam o lugar da relação agricultura-alimentação. Nesse sentido, logo quando o informante compreendia seu cotidiano e elaborava seu diálogo na entrevista, eram estruturados elementos de conexão entre a) modelo de produção centrado em alimentos e, para isso, foram expressas abordagens de trabalho com a produção diversificada de alimentos para abastecimento familiar; b) trabalho ligado à comercialização direta agricultor-consumidor, sendo enunciadas abordagens de trabalho com feiras, mercados institucionais e agroindústrias familiares rurais; c) educação para as diversas possibilidades de usos culinários e de processamentos (agroindustriais familiares) dos alimentos; d) educação para o comer, com elementos discursivos da alimentação saudável, equilibrada e segura. Algumas narrativas podem ser visualizadas no quadro 1.

A estrutura de identificação da educação alimentar e nutricional foi construída por meio de narrativas que elencavam argumentos muito particularizados de padrões de trabalho para justificar, compreender e reelaborar o seu lugar na ATES. Assim, observou-se um percurso de compreensão no qual a prática em EAN significou realizar ações sobre o consumo alimentar saudável de modo que o trabalho sobre o tema do consumo alimentar gerasse impacto sobre a prática de produção diversificada para abastecimento familiar dos agricultores. 


\section{Narrativas de Reconhecimento da EAN na ATES}

Essa questão de relação das práticas de educação alimentar com a extensão rural, ela tem um pouco a ver com minha trajetória, o olhar de que porque que eu acho que a reforma agraria é necessária? Porque eu vejo que, para construir processos de desenvolvimento numa sociedade e pra que essa sociedade tenha uma condição, uma qualidade de vida decente de se viver, precisa de uma condição básica de vida que é o alimento (E 13 - Técnico Extensionista Rural/Agrônomo - 8 anos na função).

Pra gente produzir alimentos e ter um rural diferente é preciso estar afinado com essa ideia de educação para ter uma alimentação saudável, justa (E 11 - Gestor público da coordenação do Programa/Agrônomo - 8 anos na função).

A gente faz a partilha, a troca de sementes e faz pratos [...] Eu, particularmente, tento pegar sempre coisas mais alternativas, menos industrializadas, [..] vamos usar temperos naturais, [...] tentando conciliar o que é mais saudável e o que tem no assentamento (E 12 - Técnica Extensionista Rural/Assistente Social - 4 anos na função).

A gente trabalha muito o processamento, mas é aquele processamento de fabricação do alimento, é picar o repolho, fazer uma polpa de frutas, extrair um suco. A gente trabalha muito com o processamento dos alimentos (E 7 - Técnica Extensionista Rural/Magistério - 7 anos na função).

\section{Narrativas de não reconhecimento da EAN na ATES}

É complicado porque isso [a educação alimentar e nutricional] não é do trabalho da ATES (E 1 ATP/Agrônomo -8 anos na função).

Ah, eu perceber mesmo, eu percebo que não temos feito. Esse não é um tema que surge pra nós. Não é uma demanda. Essa parte, assim, nutricional, a gente não faz, não (E 2 ATP/ Agrônomo - 8 anos na função).

Pra mim não e prioridade, não é um tema que eu posso te dizer assim: olha, esse tema é um tema que tem sido discutido, é uma prioridade. Não (E 3 ATP/Agrônomo - 5 anos na função).

Quadro 1 - Trechos das narrativas dos entrevistados que expressam o reconhecimento e não reconhecimento da Educação Alimentar e Nutricional na Assessoria Técnica, Social e Ambiental para assentamentos da Reforma Agrária

Mesmo nas narrativas de não reconhecimento, esse percurso foi elucidado. Nesse caso, embora o narrador expressasse não identificação da EAN em seu cotidiano, ele trazia, em seu discurso, o mesmo percurso de relações expostas pelos outros narradores, transitando pelo itinerário da produção-consumo. 
Analisando-se as narrativas de reconhecimento e não reconhecimento, viu-se que a diferença entre elas não se situa, estritamente, de acordo com a formação acadêmica, tendo em vista que não verificamos linearidade de discursos entre as distintas formações profissionais. No entanto observamos que algumas narrativas estavam mais próximas ao discurso formal-conceitual de EAN - comparando ao conceito do Marco de Referência de EAN para Políticas Públicas (BRASIL, 2012). Extensionistas com formação acadêmica em nutrição, serviço social e pedagogia foram aqueles mencionados, pelos entrevistados, como os colegas que ensejaram o contato com o tema, desse modo, a presença do colega com formação nessas áreas parece estar vinculada com o reconhecimento desta no fazer da ATES, podendo este, ser um elemento caracterizador para a identificação de suas práticas como sendo práticas em EAN.

O Marco de EAN (BRASIL, 2012) é um documento fruto do diálogo entre setores do governo e sociedade civil para desdobramentos dos diversos setores que trabalham com a EAN, vinculados ao processo de produção, distribuição, abastecimento e consumo de alimentos. Nas narrativas dos entrevistados, observou-se proximidade com o conceito de EAN e também com a abordagem do sistema alimentar proposto pelo Marco de EAN, em que explicita que as ações de EAN precisam abranger temas e estratégias relacionadas a todas as dimensões do sistema alimentar de maneira a contribuir para que os indivíduos e grupos façam escolhas conscientes, mas também que essas escolhas possam, por sua vez, interferir nas etapas anteriores (BRASIL, 2012, p. 25).

Ademais, assinalam-se duas principais estruturas de significados da educação alimentar e nutricional vinculada ao eixo de trabalho do social e como prática de segurança alimentar e nutricional.

\section{TRANSBORDANDO DOMÍNIOS: EDUCAÇÃO ALIMENTAR E NUTRICIONAL COMO 'SOCIAL' NA ATES}

Das narrativas, emergiram significados sobre o trabalho da educação alimentar e nutricional na ATES que se vinculam com o pertencimento dessas ações na dimensão do 'social'. Entretanto, aprofundando-se o olhar da análise e trazendo as diversas nuances dos sentidos atribuídos, constata-se que as práticas em EAN percorrem, de modo transversal, o eixo social e, também, o eixo produtivo.

Para se compreender o significado do 'social' na ATES, torna-se necessário resgatar, brevemente, onde ele se localiza na extensão rural no Brasil e no RS.

A extensão rural pode ser caracterizada como um tipo de serviço especializado, prestado por profissionais a agricultores. Teve início no final da década de 1940, reproduzindo no Brasil o modelo norte-americano. Esse modelo era centrado em cooperações com agências internacionais para promover o desenvolvimento - entendido a partir da forte ideia de civilização para o empreendimento capitalista. Esse modo de trabalho permaneceu até final da década de 1980, que ensejou o processo 'repensar a extensão rural' (DIAS, 2007, p. 6). A década de 1990 foi marcada pela assistência técnica operacionalizada pelas prefeituras municipais, enfatizando um viés majoritariamente clientelista. Em 1997, sob pressão dos movimentos sociais, foi criado o Projeto Lumiar, o primeiro serviço de assistência técnica criado especificamente para os assentados do Programa de Reforma Agrária, que impulsionou a discussão sobre o papel do Estado no provimento desse tipo de serviço (DIESEL; HAAS, 2012). 
No RS, o 'repensar a extensão rural' foi pujante no final dos anos 1990 e início dos anos 2000, e objetivou promover o debate e o olhar para o rural com a multiplicidade de cenários a ele inerente, e não só o rural enquanto sinônimo de agrícola. Caporal e Costabeber (2004) expõem que o movimento aprofundou estudos e diálogos em torno da configuração das ações extensionistas, produzindo a compreensão de que elas deveriam contemplar ações não só de natureza produtiva, ligadas ao agrícola, mas também às ações de natureza ambiental e social. Esse movimento foi um dos grandes potencializadores do chamamento para o trabalho na área social da extensão rural.

A narrativa que segue é de uma entrevistada que iniciou seu trabalho na extensão rural nesse período. Ela situa o trabalho de educação no campo da área social, valorizando o que chama de mudanças na extensão rural.

Quando eu comecei meu trabalho, a extensão rural passava por mudanças, e as mudanças éramos nós, profissionais fora do campo das ciências agrárias. Éramos nutricionistas, farmacêuticos bioquímicos, enfermeiros, engenheiro de alimentos; [...] porque se entendia que as ciências agrárias, por si só, não davam conta de todas as demandas de uma sociedade que se transformava e reivindicava novos lugares; um rural que reivindicava mais do que ele tinha recebido até então (E 4 - Técnica Extensionista Rural/Nutricionista - 8 anos na função).

As diretrizes atuais do Programa de ATES buscam o desenvolvimento dos eixos produtivo, social e ambiental a partir do reconhecimento das especificidades locais e regionais dos assentamentos. Assim, o conjunto de práticas no campo da saúde, segurança alimentar e nutricional, educação (leia-se, interlocução com o espaço escolar), artesanato, cultura, garantia de direitos, lazer, são áreas reconhecidas como de pertencimento ao eixo social. Licenciamento ambiental de atividades produtivas, manejo de recursos naturais, além de promoção, controle, monitoramento dos recursos naturais são reconhecidas como pertencentes ao eixo ambiental. Ainda, todas aquelas atividades que trabalham com a produção agropecuária e geração de renda familiar são reconhecidas como pertencentes ao eixo produtivo (INCRA, 2013).

Caporal e Costabeber (2004) e Dias (2004) ressaltam que o trabalho do técnico extensionista da área produtiva é visto com distinção frente aos demais. Essa distinção é marcada pela valoração, qualificação e maior status. Os autores observam que essa distinção é herança do período da extensão rural difusionista, moldada na produção de commodities agrícolas e decorre, em grande medida, da percepção de que este é o trabalho gerador da renda majoritária para a família.

No contexto da extensão rural difusionista, foram induzidas muitas dicotomias entre rural-urbano e moderno-atrasado, as quais impulsionaram o modelo agroalimentar atual, que estimula a produção de sementes em larga escala e reprime a manutenção da diversificação da produção agropecuária, reduz a produção de sementes tradicionais (não híbridas) e localiza o trabalho com a produção para o autoconsumo como um trabalho menor, menos valorizado (GRISA et al., 2011).

Entretanto o trabalho com a produção para autoconsumo surge ressignificado nas narrativas. Essa ressignificação pode ser observada à medida que o estabelecem enquanto elemento que transita tanto na dimensão técnico-produtiva quanto da dimensão social. E também nas expressões de valoração contidas das práticas em EAN que resgatam e promovem a produção para o autoconsumo.

Considera-se, então, o transbordamento da EAN enquanto categoria pertencente ao social, que pode ser visualizada nas narrativas que seguem: 
O Programa de ATES trabalha o produtivo, mas também o social e o ambiental. (E3 - ATP/ Agrônomo - 5 anos na função).

A melhor forma de assessorar pra fazer essa discussão do produtivo e do social passa pela produção de subsistência, diversificada. É debater a agroecologia e o estímulo ao aproveitamento dos alimentos. (E6 - ATP/Bacharel em Desenvolvimento - 5 anos na função).

Então, a gente pensa o planejamento com os técnicos, como eles vão fazer o trabalho de uma forma mais qualificada sobre o consumo, sobre a produção para subsistência. (E2 - ATP/ Agrônomo - 8 anos na função).

Observa-se que as narrativas recuperam o posicionamento produtivo versus social, mas reelaboram sua compreensão a partir de um tema aglutinador. Assim, os entrevistados percebiam o lugar das práticas em educação alimentar e nutricional no eixo orientativo do social - em uma primeira expressão - e, logo em seguida, do produtivo, articulando-as.

Pode-se considerar que a articulação entre os eixos social e produtivo expressos nas narrativas decorrem de três origens: da própria formação e vivência de trabalho do técnico; da concepção das prestadoras de serviços de ATES à qual o técnico está vinculado; e também da abordagem de trabalho proposta pelo Programa como um todo. No último caso, verifica-se que o Programa construiu duas estratégias de abordagem de trabalho no eixo social: o documento orientativo de Diretrizes e métodos para a dimensão social da ATES/RS e os instrumentos de apoio ao trabalho da ATES: Sistema de Avaliação e Monitoramento da ATES (SAMA), o Sistema Gestão da ATES (SIGRA) e a Rede de Unidades de Observação Pedagógica (RUOP) (NEUMANN; DALBIANC; ZARNOT, 2012).

O documento orientativo foi formulado em 2015, como resultado coletivo do Programa de ATES. Esse documento propõe princípios e métodos de ação para as equipes técnicas, e organiza seis eixos temáticos em suas diretrizes, sendo eles: soberania e segurança alimentar; educação e organização social; cultura, esporte e lazer; promoção da saúde; acesso a direitos básicos; geração de renda, gestão da produção, processamento e comercialização (INCRA, 2015).

As entrevistas foram marcadas pela presença desses instrumentos de apoio ao trabalho de ATES, sendo que revelavam distintas significações do fazer em educação alimentar e nutricional. Os entrevistados expressaram a importância desses instrumentos na consolidação das práticas em EAN, à proporção que possibilitou o planejamento de atividades relevantes para cada família, para cada grupo. Pode-se observar narrativas que apresentavam a utilização dos instrumentos de apoio ao diagnóstico e planejamento de suas atividades, destacando seu potencial de cruzamento de ações nos eixos social e produtivo.

E aí o que eu vejo então, que nós temos ações que perpassam ambiental, social, produtivo, tipo a sistematização de experiências agroecológicas, a própria RUOP e o SIGRA que dão elementos para pensar como está cada lote e qual é o tipo de trabalho que tem que ser feito. (E 4 - Técnica Extensionista Rural/Nutricionista - 8 anos na função).

A percepção de transbordamento da EAN da dimensão social - extravasando a unicidade dessa dimensão - trouxe um conjunto de valores com significados muito específicos e simbólicos. Esses valores foram atribuídos à característica do tipo de trabalho realizado em EAN que se relacionava ao holístico, sistêmico, global. O emprego desses termos foram usados no sentido de qualificar o trabalho do extensionistas que trabalhavam com a perspectiva de EAN. 
Todos os técnicos têm que ter esse olhar para o social, é essa visão holística, mais global. Então nosso trabalho é muito no aspecto de garantir cidadania da família rural. (E10 - Técnica Extensionista Rural/Nutricionista -8 anos na função).

Tem que olhar o todo. Desde o que se produz, como se produz, até o que se come, como se come. (E14 - Técnica Extensionista Rural/Nutricionista - 3 anos na função).

Em todas as áreas que a gente atende a gente faz a educação alimentar. Isso é a realidade do trabalho na extensão rural; quem presta assistência técnica na família diretamente não tem como falar de um tema único. (E12 - Técnica Extensionista Rural/Assistente Social - 4 anos na função).

\section{EAN APROXIMADA DA SAN}

Na área social, fizemos muito esse trabalho com educação alimentar mais na parte de segurança alimentar, né. A segurança alimentar é extremamente abrangente. O próprio técnico quando faz o trabalho com pecuária, com a produção de sementes, ele deve ter a visão para a segurança alimentar. (E17 - Técnico Extensionista Rural/Técnico Agrícola - 2 anos na função).

As narrativas apontaram para significação da EAN enquanto prática de segurança alimentar e nutricional. Na descrição do percurso das abordagens educativas, o trabalho para a promoção da produção de alimentos foi colocado como uma primeira aproximação do extensionista com o agricultor.

Torna-se importante destacar que a Lei Orgânica de SAN (BRASIL, 2006), conceitua segurança alimentar e nutricional como

a realização do direito de todos ao acesso regular e permanente a alimentos de qualidade, em quantidade suficiente, sem comprometer o acesso a outras necessidades essenciais tendo como base práticas alimentares promotoras da saúde, que respeitam a diversidade cultural e que sejam social, econômica e ambientalmente sustentáveis.

Esse conceito está estruturado em quatro dimensões, as quais orientam a operacionalização técnica e política, e também possibilita a compreensão da SAN nos seus preceitos teóricos. São dimensões da SAN: a disponibilidade do alimento, o acesso ao alimento, a utilização dos alimentos e dos nutrientes do ponto de vista orgânico/fisiológico, e a estabilidade, que é uma dimensão transversal às outras três.

A dimensão de disponibilidade diz respeito à garantia de alimentos suficientes para toda a população, o que envolve questões de produção, comércio internacional e nacional, abastecimento e distribuição de alimentos. O acesso físico e econômico aos alimentos realiza-se quando todos têm a capacidade de obter alimentos de forma socialmente aceitável, a exemplo da produção, da compra ou troca de alimentos. A utilização dos nutrientes é pensada desde o ponto de vista biológico, dos alimentos/nutrientes no organismo - o que envolve condições de saneamento básico e saúde das pessoas, e segurança microbiológica e química dos alimentos - portanto a dimensão do acesso abrange, também, o conhecimento da população acerca dos componentes nutricionais, as escolhas e hábitos alimentares, assim como o papel social da alimentação no grupo familiar e na comunidade. A estabilidade se refere ao elemento temporal das dimensões da disponibilidade, acesso e utilização. Sendo assim, a dimensão da estabilidade considera o tempo (sazonal, transitório ou crônico) na caracterização das outras três dimensões (ORGANIZAÇÃO DAS NAÇÕES UNIDAS PARA A AGRICULTURA E A ALIMENTAÇÃO [FAO], 2014). 
Ao visualizar o conceito e as dimensões da SAN, podemos identificar algumas aproximações feitas pelos entrevistados em suas narrativas, quando componentes das diferentes dimensões da SAN permearam as falas. Nas entrevistas houve forte presença do componente produção para autoconsumo alimentar como elemento aglutinador do campo da SAN, de modo que, ao elaborar sua compreensão sobre a EAN, o entrevistado apresentava termos próximos aos das dimensões da produção, abastecimento e consumo.

Desse modo, compuseram o repertório de significações das práticas em EAN as ações em torno do trabalho para promoção da produção para o autoconsumo, produção diversificada, consumo alimentar saudável, preparações culinárias e usos dos alimentos. Ainda, os temas da agroecologia e/ou redução do uso de agrotóxicos, uso de plantas medicinais e condimentares e o tema relacionado às boas práticas de manipulação de alimentos foram temas acessórios, expressos como componentes de outros arranjos necessários para a prática em EAN.

O trabalho com as práticas em EAN relacionadas à produção diversificada de alimentos para consumo familiar e os demais temas, tais como os modos de comer, as habilidades culinárias, o reconhecimento do alimento e da comida enquanto promotores da saúde podem ser observados em estudos de Scagliusi et al. (2016), Monteiro et al. (2015), Fischler (2011). Algumas narrativas apontam esse cenário:

Ah, eu percebo mesmo desse jeito, que nós fizemos a parte da educação, na segurança alimentar. É quando a gente faz dia de campo, faz plantio, elabora pratos, com mandioca, com abóbora, com batata doce. (E9 - Técnico Extensionista Rural/Técnico Agrícola - 8 anos na função).

A gente trabalha na educação e promoção da saúde, e também na segurança alimentar, que são duas áreas muito ligadas. (E16 - Técnico Extensionista Rural/Magistério - 7 anos na função).

A gente pensa na elaboração de pratos, na assessoria da horta, no pomar, fizemos muito a segurança alimentar. (E8 - ATP/Pedagoga - 5 anos na função).

É bem importante fazer a parte da segurança alimentar, trabalhar com ervas medicinais, trabalhar com a preparação do alimento, com o aproveitamento. (E12 - Técnico Extensionista Rural/Assistente Social - 4 anos na função).

O perfil do profissional e a concepção de trabalho da própria prestadora de serviços de ATES também emergiram como dimensões que influenciavam as atividades em EAN e as posicionavam enquanto segurança alimentar e nutricional, como na narrativa a seguir:

Pra [prestadora A], tem essa demanda de calcular a segurança alimentar, que é tentar estimar a renda da produção do autoconsumo. E no caso [da prestadora C] é muito mais vinculado ao discurso, ao princípio deles como organização. É mais enraizado em sua essência, do que em suas ações. Daí tem bastante diferença com [a prestadora B] que faz isso acontecer de fato, que a gente consegue ver as atividades. Para [a prestadora C] tem muito a ver com o entendimento sobre segurança alimentar do que qualquer outra coisa. (E 11-Gestor público da coordenação do Programa/Agrônomo- 8 anos na função).

Talvez por ser um tema que esteja divulgado de modo mais amplo nos espaços institucionais (documentos oficiais da Política Nacional de ATER, documentos oficiais da ATES, e também como pressuposto das próprias prestadoras de serviços de ATES) e nos espaços acadêmicos, a SAN foi um tema que se estabeleceu de modo muito próximo e, por vezes, superposto à EAN.

A PNATER (BRASIL, 2010) reconhece a SAN em seu texto, trazendo-a enquanto um de seus objetivos específicos: a realização de ações de assistência técnica e extensão rural que auxiliem a 
garantia da SAN. Outros documentos da ATES, como os Projetos Básicos (INCRA, 2008) propõem a promoção da SAN. Além destes, as próprias prestadoras de serviços de ATES trazem em suas concepções de trabalho a proximidade com a SAN (MOVIMENTO DOS TRABALHADORES SEM TERRA [MST], 2015). A presença da segurança alimentar e nutricional nos documentos da ATES pode representar a articulação entre esses setores, a qual, de algum modo, também é revelada nas narrativas.

Esse componente de articulação entre segurança alimentar e nutricional no fazer da ATES é identificado pela constante relação que os entrevistados fazem entre produção e consumo de alimentos. Esse relato figura como um componente presente na significação da educação alimentar e nutricional enquanto segurança alimentar e nutricional. Outrossim, marca a presença do comer/do consumo alimentar no trabalho da ATES.

Autoras como Barbosa et al. (2013) e Portilho (2009) apontam que há reconhecimento de que o consumo alimentar tem se fortalecido enquanto categoria analítica política e social. Ao longo das últimas décadas, em um movimento mundial e brasileiro, esse campo tem se aproximado de valores cívicos e democráticos, como direitos, equidade, ética, sustentabilidade e responsabilidade social.

Essa tendência traz para o consumo uma mudança no sentido de ser, de sua perspectiva de olhar o mundo (FISCHLER, 2011 ; CANESQUI; GARCIA, 2005). Desse modo, pode-se observar que, na ATES, talvez essa aproximação seja a materialidade dos conceitos de sistema alimentar, que considera não só as etapas, mas sim os processos existentes no fazer da comida: alimentos, produtores, processadores e comedores.

\section{CONSIDERAÇÕES FINAIS}

Situando-se nos espaços da educação não formal, os extensionistas rurais desenvolvem práticas em educação alimentar e nutricional, construídas e reconstruídas nas dinâmicas das relações de trabalho e vivências. Potencializam-se como sujeitos de processos de ruptura e de permanências de percepções, valores e significados de seu trabalho.

A percepção sobre a educação alimentar e nutricional no trabalho de assessoria técnica, social e ambiental estrutura-se em continuidades e rupturas de processos históricos recentes. Sobre a primeira, observa-se a vinculação com o eixo de trabalho da dimensão social, e, sobre a segunda, a vinculação com o eixo de trabalho da dimensão produtiva. A segurança alimentar e nutricional é conceito próximo do cotidiano de trabalho dos extensionistas rurais, o que influencia a sobreposição deste sobre o conceito de educação alimentar e nutricional.

Destaca-se, ainda, que, por ser espaço em que o encontro e a vivência entre os sujeitos são base do trabalho, os serviços de ATES potencializam a produção do cuidado em saúde. Tendo em vista que as práticas em educação alimentar e nutricional são permeadas de construção e desconstrução de conceitos e valores sobre a produção de alimentos e a alimentação humana, localiza-se essa perspectiva como um desafio a ser enfrentado na concepção terapêutica do cuidado.

Nos últimos anos, houve reflexão e reelaboração de importantes políticas públicas como a Política Nacional de Alimentação e Nutrição, Política Nacional de Promoção da Saúde, Política Nacional de Assistência Técnica e Extensão Rural, que reposicionaram as intencionalidades e compromissos com a agenda da saúde e da segurança alimentar e nutricional. Há, nesses docu- 
mentos, uma clara confluência em suas prioridades no sentido de expandir e qualificar a garantia as ações da saúde e da segurança alimentar e nutricional.

Vislumbra-se a necessidade de avanços, com adesão política, institucional e popular para o fortalecimento de sistemas públicos de saúde e de segurança alimentar e nutricional - Sistema Único de Saúde (SUS) e Sistema Nacional de Segurança Alimentar e Nutricional de (SISAN). SUS e SISAN, articulados, somam aspectos concretos para a organização de um sistema alimentar orientado pela produção de alimentos em detrimento à produção de commodities; orientado pela produção local/regional, e não pela orientação externa/internacional; orientado pela diversidade produtiva, reduzindo a homogeneização no consumo alimentar; orientado pela produção e processamento camponês e familiar, reduzindo a inserção de produtos alimentares ultraprocessados. Para isso, a necessidade de articulação entre saúde, educação e desenvolvimento social para as populações do campo e da cidade são desafios constantes.

\section{REFERÊNCIAS}

BARBOSA, Lívia et al. Trust, participation and political consumerism among Brazilian youth. Journal of Cleaner Production, n. 63, p. 93-101, 2013.

BOOG, Maria C. F. Educação em nutrição: integrando experiências. Campinas, SP: Komedi, 2013.

. Dificuldades encontradas por médicos e enfermeiros na abordagem de problemas alimentares. Revista de Nutrição, Campinas, SP, v. 12, n. 3, p. 261-72, 1999.

BRASIL. Ministério do Desenvolvimento Social e Combate à Fome. Secretaria Nacional de Segurança Alimentar e Nutricional. Marco de referência de educação alimentar e nutricional para as políticas públicas. Brasília, DF: MDS Ministério do Desenvolvimento Social e Combate à Fome, 2012.

Ministério do Desenvolvimento Agrário. Secretaria da Agricultura Familiar Departamento de Assistência Técnica e Extensão Rural. Política Nacional de Assistência Técnica e Extensão Rural. Brasília, 2010.

Presidência da República. Casa Civil. Lei n. 11.346, de 15 de setembro de 2006. Cria o Sistema Nacional de Segurança Alimentar e Nutricional - SISAN com vistas em assegurar o direito humano à alimentação adequada e dá outras providências. Disponível em: <http://www.planalto.gov.br/ccivil_03/_ ato2004-2006/2006/lei//11346.htm>. Acesso em: 23 abr. 2017.

CANESQUI, Ana M.; GARCIA, Rosa W.D. Uma introdução à reflexão sobre a abordagem sociocultural da alimentação. In: CANESQUI, Ana M.; GARCIA, Rosa W. D. (Org.). Antropologia e nutrição: um diálogo possível. Rio de Janeiro: FIOCRUZ, 2005.

CANESQUI, Ana M. Estudos antropológicos sobre adoecidos crônicos. In: CANESQUI Ana M. (Org.). Olhares antropológicos sobre adoecidos crônicos. São Paulo: HUCITEC-FAPESP, 2007. p. 19-51.

CAPORAL, Francisco R.; COSTABEBER, José A. Agroecologia e extensão rural: contribuições para a promoção do desenvolvimento sustentável. Brasília: MDA/SAF/DATER-IICA, 2004.

DIAS, Marcelo M. Extensão rural para qual desenvolvimento? In: DIAS, Marcelo M. (Org.). Abordagens atuais sobre extensão rural. Viçosa, MG: Universidade Federal de Viçosa, 2007.

DIAS Marcelo M. Extensão rural para agricultores assentados: uma análise das boas intenções propostas pelo 'Serviços de Ates". Cadernos de Ciência \& Tecnologia, Brasília, v. 21, n. 3, p. 499-543, 2004.

DIESEL, Vivien; HASS, Jaqueline M. Transições metodológicas: atuação extensionista na elaboração dos PDA e PRA na ATES do RS. In: DIESEL, Vivien; NEUMANN, Pedro S.; SÁ, Vinicius C. de (Org.). Extensão rural no contexto do pluralismo institucional: reflexões a partir dos serviços de Ates aos assentamentos da reforma agrária no RS. Ijuí, RS: Ed. da Unijuí, 2012. p. 271-306.

INTERAÇÕES, Campo Grande, MS, v. 18, n. 3, p. 41-54, jul./set. 2017. 
FISCHLER Claude; MASSON, Estelle. Comer: a alimentação de franceses, outros europeus e americanos. São Paulo: SENAC, 2010.

FISCHLER, Claude. Commensality, society and culture. Social Science Information, n. 50, p. 528-48, 2011. FREIRE, Paulo. Extensão ou comunicação? São Paulo: Paz e Terra, 1983.

GOMES Romeu. Análise e interpretação de dados de pesquisa qualitativa. In: MINAYO Maria C. S. (Org.). Pesquisa social: teoria, método e criatividade. 33. ed. Petrópolis, RJ: Vozes, 2013. p. 79-107.

GRISA, Cátia et al. Contribuições do Programa de Aquisição de Alimentos à segurança alimentar e nutricional e à criação de mercados para a agricultura familiar. Agriculturas, v. 8, n. 3, p. 34-41, 2011.

INSTITUTO NACIONAL DE COLONIZAÇÃO E REFORMA AGRÁRIA (INCRA). Universidade Federal de Santa Maria (UFSM). Programa de Assessoria Técnica, Social e Ambiental de ATES/RS. Termo de Cooperação Técnica UFSM/INCRA, Assessores Técnicos Pedagógicos. Diretrizes e métodos para a dimensão social na ATES/RS. Porto Alegre, 2015.

Projeto básico visando à licitação para a prestação de Serviços de Assessoria Técnica, Social e Ambiental (ATES), e elaboração de PDA ou PRA para as famílias assentadas no estado do Rio Grande do Sul. Porto Alegre, 2013.

. Manual operacional de Assessoria Técnica, Social e Ambiental à Reforma Agrária. Norma de execução n. 78, 31 de outubro de 2008. Brasília, 2008.

MONTEIRO, Carlos A. et al. Dietary guidelines to nourish humanity and the planet in the twenty-first century: a blueprint from Brazil. Public Health Nutrition, n. 24, p.1-12, 2015.

MOVIMENTO DOS TRABALHADORES SEM TERRA (MST). Setor de Educação. Alimentação saudável: um direito de todos. Jornada Cultural Nacional. Boletim da Educação, São Paulo, n. 13, 2015.

NEUMANN, Pedro S.; DALBIANCO, Vinicius P.; ZARNOT, Alisson V. A política pública de extensão rural em assentamentos da reforma agrária: a construção de um sistema pluralista descentralizado. In: GRISA, Cátia; SCHNEIDER, Sérgio. Políticas públicas de desenvolvimento rural no Brasil. Porto Alegre, RS: Ed. da UFRGS, 2015. p. 401-28.

ORGANIZAÇÃO DAS NAÇÕES UNIDAS PARA A AGRICULTURA E A ALIMENTAÇÃO (FAO). O estado da segurança alimentar e nutricional no Brasil: um retrato multidimensional. Relatório 2014. Brasília, 2014.

PORTILHO, Fátima. Novos atores no mercado: movimentos sociais econômicos e consumidores politizados. Revista Política e Sociedade, n. 8, p. 199-224, 2009.

RITCHIE, Jane; LEWIS, Jane; ELAM, Gilliam. Designing and selecting samples. In: RITCHIE, Jane; LEWIS, Jane. Qualitative research practice: a guide for social science students and researchers. London: SAGE Publications, 2003. p. 77-108.

SCAGLIUSI, Fernanda B. et al. Eating at the table, on the couch and in bed: an exploration of different locus of commensality in the discourses of Brazilian working mothers. Appetite, n. 103, p. 80-6, 2016.

\section{Sobre as autoras:}

Nádia Rosana Fernandes Oliveira: Nutricionista graduada pelo Centro Universitário Franciscano, Mestre em Extensão Rural pela Universidade Federal de Santa Maria (UFSM) e Doutora em Ciências pela Faculdade de Saúde Pública pela Universidade de São Paulo (USP). Professora Adjunta do Curso de Nutrição da Universidade Federal do Pampa, Campus Itaqui. E-mail: nadia.rfo@gmail.com

Patricia Constante Jaime: Nutricionista. Professora associada do Departamento de Nutrição da Faculdade de Saúde Pública (FSP) da Universidade de São Paulo (USP). Mestre e Doutora em 
Saúde Pública pela FSP/USP. Pós-Doutora em Epidemiologia Nutricional pelo Núcleo de Pesquisas Epidemiológicas em Nutrição e Saúde (NUPENS/USP) e em Políticas Públicas de Alimentação e Nutrição pela London School of Hygiene and Tropical Medicine, Reino Unido. Faculdade de Saúde Pública da Universidade de São Paulo. E-mail: constant@usp.br 